\title{
Structures and Functions of Snake Venom Metalloproteinases (SVMP) from Protobothrops venom Collected in Japan
}

\author{
Etsuko Oyama * and Hidenobu Takahashi ${ }^{\dagger}$ \\ Department of Hygienic Chemistry, Meiji Pharmaceutical University, 2-522-1 Noshio, Kiyose-shi, \\ Tokyo 204-8588, Japan; h-taka@my-pharm.ac.jp \\ * Correspondence: oyama@my-pharm.ac.jp; Tel./Fax: +81-42-495-8596 \\ † Emeritus Professor.
}

Received: 26 June 2017; Accepted: 31 July 2017; Published: 4 August 2017

\begin{abstract}
Snake venom metalloproteinases (SVMP) are widely distributed among the venoms of Crotalinae and Viperidae, and are organized into three classes (P-I, P-II and P-III) according to their size and domain structure. P-I SVMP are the smallest SVMP, as they only have a metalloproteinase (M) domain. P-II SVMP contain a disintegrin-like (D) domain, which is connected by a short spacer region to the carboxyl terminus of the M domain. P-III SVMP contain a cysteine-rich (C) domain, which is attached to the carboxyl terminus of the D domain. Some SVMP exhibit hemorrhagic activity, whereas others do not. In addition, SVMP display fibrinolytic/ fibrinogenolytic (FL) activity, and the physiological functions of SVMP are controlled by their structures. Furthermore, these proteinases also demonstrate fibrinogenolytic and proteolytic activity against synthetic substrates for matrix metalloproteinases and ADAM (a disintegrin and metalloproteinase). This article describes the structures and FL, hemorrhagic, and platelet aggregation-inhibiting activity of SVMP derived from Protobothrops snake venom that was collected in Japan.
\end{abstract}

Keywords: snake venom metalloproteinase; fibrinolytic/fibrinogenolytic activity; hemorrhagic activity; inhibitior of platelet aggregation

\section{Introduction}

Marked hemorrhaging, edema, necrosis, thrombogenesis, hypotension, and pain are observed immediately after snakebites involving Viperidae or Crotalinae. These symptoms are caused by a bioactive mixture of proteinases, phospholipase $\mathrm{A}_{2}$, phosphodiesterase, $5^{\prime}$-nucleotidase, L-amino acid oxidase, peptides, and C-type lectins [1] Proteinases are considered to be one of the main elements that cause these symptoms. Proteinases are present in the venoms of many snakes and are structurally classified into trypsin-type snake venom serine proteases (SVSP) and snake venom metalloproteinases (SVMP).

SVMP are organized into three classes according to their size and domain composition [2]. Phylogenetically, SVMP are most closely related to the mammalian ADAM (a disintegrin and metalloproteinase) family [3]. Class P-I SVMP are the smallest SVMP, as they only have a metalloproteinase (M) domain. Class P-II SVMP contain a disintegrin-like (D) domain, which is connected by a short spacer region to the carboxyl terminus of the M domain [4]. Class P-III SVMP contain a cysteine-rich (C) domain on the carboxyl side of the D domain.

Protobothrops (habu) is classified into the Crotalinae family, and P. flavoviridis (Hon habu), P. elegans (Sakishima habu), and P. tokarensis (Tokara habu) are all found in Japan. Snake venom metalloproteinases (SVMP) account for at least 30\% of the components of most Protobothrops venoms, suggesting that SVMP play significant roles in envenomation-related pathologies, such as bleeding, 
intravascular clotting, edema, thrombogenesis, inflammation, and necrosis [5-8]. In particular, SVMP are the primary factors responsible for hemorrhaging [9]. A non-hemorrhagic $\mathrm{H}_{2}$ proteinase $\left(\mathrm{PF}-\mathrm{H}_{2}\right)$ and four hemorrhagic proteinases (HR1A, HR1B, HR2a, and HR2b) were isolated from P. flavoviridis venom collected in Okinawa. SVMP have various physiological functions, e.g., they exhibit fibrinolytic/fibrinogenolytic (FL) and hemorrhagic activity, activate prothrombin, induce apoptosis in vascular endothelial cells, and affect platelet aggregation. The relationship between the structures and functions of metalloproteinase/disintegrin/cysteine-rich (MDC) domains has been reported previously, and specific functions of SVMP were suggested to be dependent on the structures of these domains $[3,7,10,11]$. Structural comparisons between SVMP revealed differences in the features of the substrate-binding region of the $\mathrm{M}$ domain; however, no relationship was found between these structural differences and hemorrhagic activity [12]. This article describes the structures and FL, hemorrhagic, and platelet aggregation-inhibiting activities of SVMP that were isolated from Protobothrops (P. flavoviridis, P. elegans, and P. tokarensis) venoms collected in Japan.

\section{Classification of the Domain Structures of SVMP}

SVMP range in size from 20 to $100 \mathrm{kDa}$ and have been classified into three groups, P-I to P-III (Figure 1), according to their domain structures [13]. Class P-I SVMP are the smallest SVMP, as they only contain an M domain (position 1-214). Class P-II SVMP contain a canonical D domain (position 219-307), which is connected by a sort spacer region to the carboxyl terminus of the M domain. Class P-III SVMP contain a C domain (position 308-432), which is located on the carboxyl side of the D domain. Single-chain class P-III SVMP, including the HR1A and HR1B isolated from P. flavoviridis venom [14,15], have been subclassified as P-IIIa. In addition, P-III SVMP have been further divided into subclasses based on their post-translational modifications, such as whether they are subjected to dimerization (P-IIIc) or proteolytic processing (P-IIIb). P-IIId SVMP, for example, a specific factor X activator derived from Russell's viper (Daboia russelli) venom (RVV-X) contains an additional C-type lectin-like domain $[16,17]$.
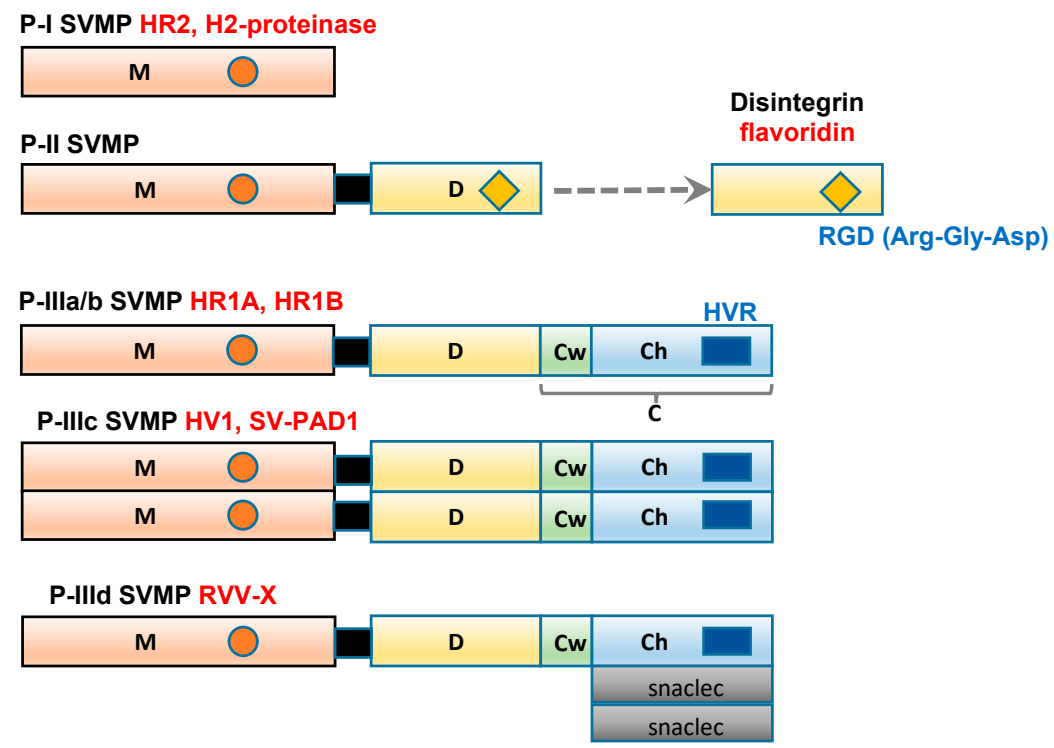

Figure 1. Schematic diagram of the domain structures of P-I, P-II, and P-III SVMP Each domain or subdomain is represented by a different color. M: metalloprotease domain (orange); D: disintegrin domain (yellow); C: cysteine-rich domain; Cw: the cysteine-rich "wrist" subdomain (light green); Ch: the cysteine-rich "hand" subdomain (light blue); HVR: hypervariable region (dark blue); snaclec: snake venom C-type lectin-like domain (grey). 


\section{Structures and Characterization of SVMP}

The M domain of SVMP contains a conserved $\mathrm{Zn}^{2+}$-binding sequence (His-Glu-X-X-His-X-X-GlyX-X-His; positions 145-155) and a Met-turn (Met ${ }^{173}$ ) bearing the typical structural features of the metzincin family of metalloproteinases [18]. The amino terminus of the upper $\mathrm{M}$ domain of $\mathrm{PF}-\mathrm{H}_{2}$ [19] has a central core consisting of a highly twisted five-stranded $\beta$-sheet and four $\beta$-helices (Figure 2 ). The carboxyl terminus of the lower $\mathrm{M}$ domain consists of a C-terminal helix preceded by an irregular region. This irregular region is presumably important for substrate recognition because it forms part of the wall of the substrate-binding pocket [3]. In SVMP, about $26 \%, 40 \%$ and $50 \%$ of the amino acid sequences of the $\mathrm{M}, \mathrm{D}$, and $\mathrm{C}$ domains, respectively, are conserved (Figure 3). As for the amino acid sequences of the SVMP found in Protobothrops venom, most differences were detected in the M domain. In particular, most of the variation was found in three regions (positions 26-35, 70-79 and 92-117) (Figure 3A). As shown in Figure 2, positions 26-35, 70-79 and 92-117 are located in $\alpha 2-, \alpha 3-$ helices, and $\beta 3$-sheet, respectively. It is suggested that these three regions influence the substrate specificity of P-I SVMP.

\section{A}

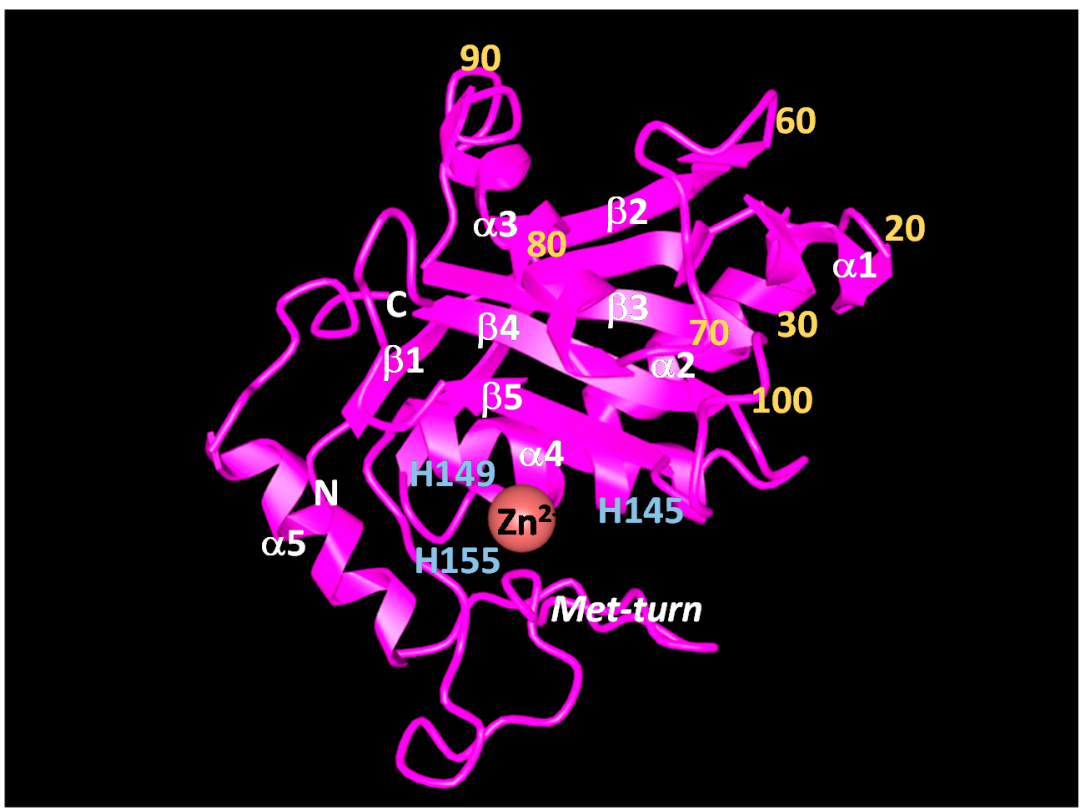

B

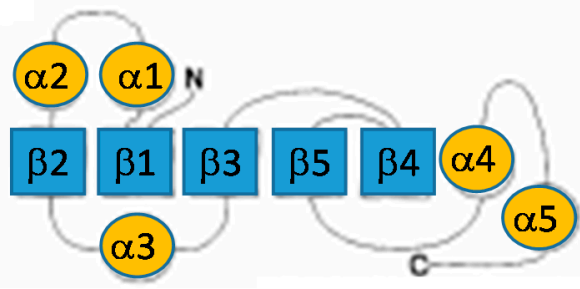

Figure 2. (A) Three-dimensional structure of the $\mathrm{M}$ domain of an $\mathrm{H}_{2}$-proteinase derived from Protobothrops flavoviridis venom [19]. $\alpha 1-\alpha 5$ : $\alpha$-helices; $\beta 1-\beta 5$ : $\beta$-sheet; Yellow number shows amino acid position; Light blue shows His residues in $\mathrm{Zn}^{2+}$-binding sequence; (B) Topological packing diagrams for $\mathrm{H}_{2}$-proteinase derived from $P$. flavoviridis venom. 
1. $\mathrm{PTH}_{2}$

2. $\mathrm{PFH}_{2}$

3. HR2a

4. HR2

5. Flavor. Pre

6. Eleg.Pre

7. HRIA

8. HR1B

9. HV1

consensus

1. $\mathrm{PTH}_{2}$

2. $\mathrm{PFH}_{2}$

3. $\mathrm{HR} 2 \mathrm{a}$

4. HR2b

5. Flavor.pre

6. Eleg.pre

7. HRIA

8. HR1B

9. HV1

consensus

1. $\mathrm{PTH}_{2}$

2. $\mathrm{PFH}_{2}$

3. HR2a

4. HR $2 \mathrm{~b}$

5. Flavor.Pre

6. Eleg.Pre

7. HRIA

8. HR1B

9.

Consensus

5. Flavor.pre

6. Eleg.pre

7. HRIA

8. HRIB

9. HV1

consensus

5. Flavor.pre

6. Eleg.pre

7. HR1A

8. HR1B

9. HV1

consensus

<E-RF- - PQRYIELAIVVDHGMYKKYNQNSDKIKVRVHQMVNHINEMYRPLNIAISLNRLQIWSKKDLITVKSA $<E-R F-$ - PQRYIELAIVVDHGMYKKYNQNSDKIKVRVHQMVNHINEMYRPLNIAISLNRLQIWS KKDLITVKSA <EORF - - PORYIELAIVVDHGMYTKYSSNFKKIRKRVHOMVNNINHMYRPLNIAITLSLLDVWSEKDLITMOAV $<$ EQRFRFPORYIEIAIVVDHGMYTKYSSNFKKIRKRVHOMVNNINEMYRPLNTAITLSLIDVWSEKDLITMOAV $<$ EQRF - - PQRYIELAIVVDHGMYKKYNHDSDKIKVRVHQMVNHINEMYRPLNIAITLSLLQIWSNKDLITVKSA $<E Q R F$ - - PQRYIKLA IVVDHGMY IKYSSNFKKIRKRVHQMVSNINEMCRPLNIAITLALLDVWSEKDFITVQAD $<$ EQRYLNNFRFIELVIVADYRMFTKFNSNLNEVKTWVYEIVNTLNELYRYLYVRVALVALEVWSNGDLSSVTLS $<$ EQRF-- PRRYI KLAIVVDHGIVTKHHGNLKKIRKWIYQLVNTINNIYRSLNILVALVYLEIWS KQNKITVQSA TPAQQKYLNAKKYVKFFLVADHIMYLKYGRNLTTLRTMFDTVNIVNQILQRI -NIHVALIGIEIWSKEDKI IVQSV -

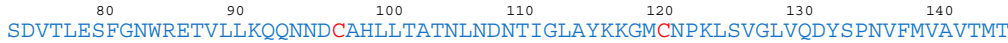
SNVTLESFGNWRETVLLKOONNDCAHLLTATNLNDNTI GLAYKKGMCNPKLSVGLVODYS PNVFMVAVTMT APTTARLFGDWRETVLLKQKDHDHAQLLTDINFTGNTIGWAYMGGMCNAKNSVGIVKDHSSNVFMVAVTMT APTTARLFGNWRETVLLKQKDHDHAQLLTDINFTGNTI GWAYMGGMCNAKNSVGIVKDHS SNVFMVAVTMT SNVTLNLFGNWRETVLLKRRSHDCAHLLTDINFTGNI IGLAYKQGMCNPKLSVGLVQDYSSNVFVVAVIMT APTTAGLFGDWRERVLLKKKNHDHAQLLTDTNFARNTI GWAY - LGMCDEKY SVGVVODHS SKVFMVAVTMT AYDTLDSFGEWRKRDLLKRKSHDNAQLLTAIDFNGTI IGLAHVASMCDPKCSTGIVQDYSSRNLVVAVIMA SNVTLDLFGDWRESVLLKQRSHDCAQLLTTIDFDGQTIGKAYTASMCDPKRSVGIVQDYSP INLVVAVIMT PDVTLKLFATWRESVLLKRKNHDNAHLLTGINFNGPTAGLAYLGGICKPMI SAGIVQDHNKIHHLVAIAMA - - - T- - - F--WR- - -LLK- - - -D - - -LLT- - - - - - T-G-A- - - - C- - - S-G-V-D- - - - - -VA--M

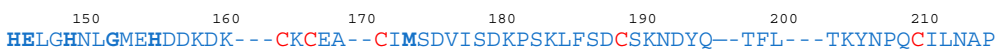
HELGHNLGMEHDDKDK-- CKCEA- - CIMSDVISDKPSKLFSDCSKNDYQ- - TFL - - TKYNPQCILNAP HEIGHNLGMEHDDKDK- - CKCEA - - CIMSAVISDKPSKLFSDCSKDYYQ--TFL - - TNSKPQC I INAP HEIGHNLGMEHDDKDK - - - CKCEA - - CIMSAVI SDKPSKLF SDCSKDYYO-- TFL - - - TNSKPOCI INAP HELGHNLGMEHDEEKNGKKCNCKT--CIMSPAISDPPAQLFSDCSKNDYH--TFL - - TNRNPOCILNAPLRTD HELGHNLGMEHDDKDK - - CKCEA--CIMSAVISDKQSKLFSDCSKDYYQ--TFL - - - TNDNPQCILNAPLRTD HEMGHNLGIRHDR - EN - - CTCHANSCIMSAVISDQPSKYFSNCSHVQY--WNYI - - -NDPEPQCILNEPLRTD HEMGHNLGI PHDG-NS - - CTCGGFPCIMSPMI SDPPSELFSNCS KAYY--GTFL - - TDHKPOCILNAPSKTD HEMGHNL GMDHD - KDT - - CTCRAKACVMAGTLSCDASYLFSDCSR--OEHRAFL - - - IKNMPOCILKKPLKTD

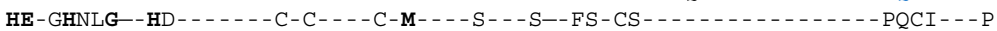

\title{
(A)
}

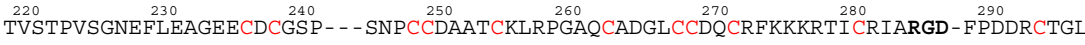
TVSTPVSGNEFLEAGEECDCGSPE - - NPCCDAATCKLRPGAQCADGLCCDQCRF IEEGI I CRRARGD-DLDDYCNG I IVSPPVCGNELLEVGEECDCGSPATCRYPCCDAATCKLHSWVECESGECCEQCRFRTAGTECRARRSECDIAESCTGH IVSPPVCGNELLEAGEECDCGSPENCOYOCCDAASCKLHSWVKCESGECCDOCRFRTAGTECRAAESECDIPESCTGQ VVSPPVCGNYFVEVGEDCDCGAPATCRDPCCDAATCKLRQGAQCAEGLCCDQCRFKAAGTECRAATDECDMADLCTGR -VS-PVCGN - - - E-GE-CDCG - P - - - - - CCDAA-CKL - - - - C-- G- CC-QCRF- - - - - CRA - - - - - - - - C- G-

$\begin{array}{llllll}300 & 310 & 320 & 330 & 340 & 350\end{array}$

SGDCPRNPFHA

SADCPTDRFHRNGQPCLHNFGYCYNGNCPIMYHQCYALWGANATVAKDSCFEDNOKGNDYGYCRKENGRKIP SADCPTDRFHRNGOPCLYNHGYCYNGKCPIMFYOCYFLFGSNATVAEDDCFNNNKKGDKYFYCRKENEKYIP SAEC-TDRFQRNGQPCQNNNGYCYNRTCPTMNNQCIALFGPNAAVSPDACFQFNRQGNYYGYCRKEQNTKIA S--C-TDRF-RNGQPC--N-GYCYN--CP-M--QC--L-G-NA-V--D-CF--N--G--Y-YCRKE--- - I -

5. Flavor.pre

6. Eleg.pre

7. HRIA

8. HR1B

9. HV1

consensus

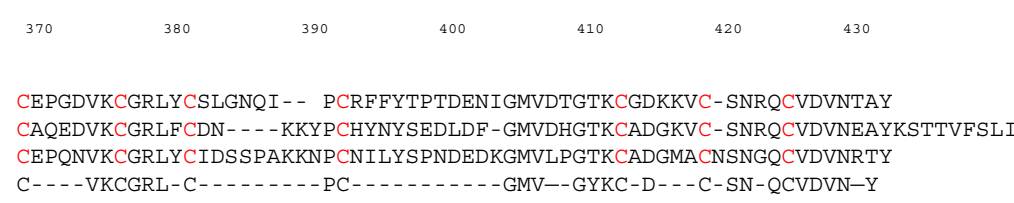

(B)

Figure 3. Comparison of the amino acid sequences of $\mathrm{PT}-\mathrm{H}_{2}$ with those of other Protobothrops venom metalloproteinases. (A) Amino acid sequences of the M domains of SVMP; (B) Amino acid sequences of the DC domains of P-II and P-III SVMP. Gaps have been introduced to facilitate comparisons of sequence similarity. $<\mathrm{E}$ is pyroglutamic acid. The cysteine residues are shown in red. The binding site for $\mathrm{Zn}^{2+}$ and the Met-turn amino acid residues are shown in bold. The amino acid sequence of $\mathrm{PT}-\mathrm{H}_{2}$ and the conserved amino acid residues are shown in blue. M domain: position 1-214; D domain: position 219-307; C domain: position 308-432; $\mathrm{PTH}_{2}$ : a non-hemorrhagic P-I SVMP derived from P. tokarensis venom [20]; $\mathrm{PFH}_{2}$ : a non-hemorrhagic P-I SVMP derived from P. flavoviridis venom [21]; HR2a [22] and HR2b [23]: hemorrhagic P-I SVMP derived from P. flavoviridis venom; Flavor. pre: a flavoridin precursor (a disintegrin) derived from P. flavoviridis venom [24]; Eleg. pre: a precursor of elegantin (a disintegrin) derived from P. elegans venom [25]; HR1A and HR1B [14]: hemorrhagic P-IIIa/b SVMP derived from P. flavoviridis venom; HV1 [26]: an apoptotic P-IIIc SVMP derived from P. flavoviridis venom 
P-I SVMP are single-chain polypeptides with molecular masses of about $25 \mathrm{kDa}$ (200-210 amino acid residues). The proteolytic activities of these enzymes are not influenced by $p$-APMSF ( $p$-amidino-phenylmethylsulfonyl fluoride hydrochloride, an inhibitor of serine proteases), but are completely inhibited by EDTA (ethylenediaminetetraacetic acid). P-I SVMP are the smallest SVMP, as they only have an M domain. Therefore, the hemorrhagic and proteolytic activities of P-I SVMP are generally weaker than those of P-III SVMP, which have a C domain containing a hypervariable region (HVR) (positions 382-403 in Figure 3B). The HVR segment is considered to recognize substrates for P-III SVMP during protein-protein interactions $[3,27,28]$.

P-II SVMP contain a canonical D domain, which is connected by a sort spacer region to the carboxyl terminus of the $\mathrm{M}$ domain. In general, snake venom disintegrins are generated by the proteolytic processing of large precursor P-II SVMP [29-31], although there is an exception to this rule [32]. Disintegrins typically possesses an Arg-Gly-Asp (RGD) recognition sequence in an extended loop (RGD loop), which inhibits integrin-mediated platelet aggregation and cell-matrix interactions [33,34].

P-III SVMP are classified into the following subclasses: P-IIIa/b, which exhibit hemorrhagic and proteolytic activity and inhibit platelet aggregation; P-IIIc, which induce apoptosis in human umbilical vein endothelial cells (HUVEC); and P-IIId, which activate factor X or prothrombin. When the amino acid sequences of the DC domains of class P-II integrin precursors (flavoridin [24] and elegantin [25]), class P-IIIa/b hemorrhagic SVMP (HR1A and HR1B [14]), and a P-IIIc HUVEC apoptosis inducer (HV1 [26]) were compared, it was found that the SVMP within the same class displayed a high degree of homology. The biological activities of SVMP are shown in Table 1. Interestingly, among the class P-III SVMP, the SVMP within the same subclass tended to have similar physiological functions. Furthermore, the HVR segments of these SVMP also demonstrated a high degree of homology among the P-III SVMP with similar physiological functions. It is suggested that the HVR segment might be an additional protein-binding site $[3,27,28]$.

Table 1. Characterizations and biological activities of SVMPs from Protobothrops venom in Japan.

\begin{tabular}{|c|c|c|c|c|c|}
\hline & Class & Domains & Sorce & $\begin{array}{l}\text { Biological } \\
\text { Activities }\end{array}$ & \\
\hline HR1B & P-IIIa/b & MDC & P. flavoviridis & Hemorrhagic & \\
\hline HR-Ele-1 & $\mathrm{P}-\mathrm{III} / \mathrm{b}$ & MDC & P. elegans & Hemorrhagic & \\
\hline HV1 & P-IIIC & MDC (dimer) & P. flavoviridis & N.D. & Appoptotic \\
\hline Elegantin Pre. & P-II & MD & P. elegans & N.D. & Precursor of disintegrin \\
\hline \multirow{4}{*}{$\begin{array}{c}\text { HR2a } \\
\text { HR2b } \\
\mathrm{H}_{2} \text { proteinase } \\
\text { PT- } \mathrm{H}_{2} \\
\text { proteinase }\end{array}$} & P-I & $\mathrm{M}$ & P. flavoviridis & Hemorrhagic & \\
\hline & P-I & $\mathrm{M}$ & P. flavoviridis & Hemorrhagic & \multirow{3}{*}{$\begin{array}{c}\text { Proteolytic } \\
\text { Fibrinolytic, inhibition of platelet } \\
\text { aggregation }\end{array}$} \\
\hline & P-I & M & P. flavoviridis & Non-hemorrhagic & \\
\hline & P-I & M & P. tokarensis & Non-hemorrhagic & \\
\hline
\end{tabular}

N.D.: not determined.

\section{FL Activity}

FL enzymes and thrombin-like enzymes are widely distributed among the venoms of Crotalinae and Viperidae. The FL enzymes and thrombin-like enzymes found in snake venom act on fibrinogen and fibrin, leading to the defibrinogenation of blood and fibrinolysis, which reduces blood viscosity [35-37]. The FL enzymes present in snake venom include both SVSP and SVMP. The FL activity of SVSP derived from P. elegans venom, such as elegaxobin I and II [38], preferentially results in the release of FPA from the fibrin $\alpha$ chain rather than FPB from the fibrin $\beta$ chain, which causes incomplete fibrin clotting and a consequent increase in fibrinolytic activity. Furthermore, the fibrin fibers produced by thrombin-like SVSP are unstable and more susceptible to plasmin proteolysis than those produced by thrombin, and are therefore promptly degraded. TSV-PA belongs to a family of trypsin-type SVSP [39]. 
Tissue-type plasminogen activator-like SVSP, such as TSV-PA and the plasminogen activator present in Lachesis muta venom (LV-PA) [40], specifically cleave the $\mathrm{Arg}^{561}$ Val $^{562}$ bond in plasminogen to generate two-chain plasmin, which results in fibrinolytic activity [41,42].

The FL activity of SVMP involves the selective cleavage of the A $\alpha$ chain of fibrinogen rather than the $B \beta$ chain; however, these proteinases do not produce fibrin clots. On the other hand, this is not the case for some of SVMPs found in the venoms of Trimeresurus mucrosquamatus [43] or Crotalus atrox [44], which degrade the $\beta$ chain and $\gamma$ chain, respectively. Furthermore, P-I SVMP, such as a $\mathrm{H}_{2}$ proteinase derived from P. tokarensis venom (PT-H ${ }_{2}$ [20] and FE-32kDa (a 32-kDa fibrinolytic enzyme) from Gloydius blomhoffii sinaiticus venom [45], can promptly dissolve fibrin plates, although their fibrinolytic activity is weaker than that of urokinase (Figure 4A). Interestingly, the $\mathrm{PF}-\mathrm{H}_{2}$ proteinase [21] found in P. flavoviridis venom, in which the Asp ${ }^{75}$ residue of the $\mathrm{PT}-\mathrm{H}_{2}$ proteinase from $P$. tokarensis venom has been replaced with an $\mathrm{Asn}^{75}$ residue (Figure 3), is not able to dissolve fibrin plates [20]. While all of the $\mathrm{PF}-\mathrm{H}_{2}$ proteinase molecules extracted from $P$. flavoviridis venom exhibited the same amino acid sequence, various sugar chains were found at position 75 (Asn-X-Thr). It is suggested that Asp ${ }^{75}$ is an important amino acid residue for fibrinolytic activation because $\mathrm{PT}-\mathrm{H}_{2}$ proteinase has a different substrate specificity from $\mathrm{PF}-\mathrm{H}_{2}$ proteinase.

A

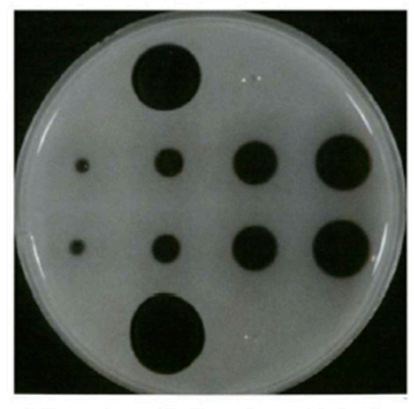

Diameter of dissolved circle $(\mathrm{mm})$

UK (0.6 U): $16 \mathrm{~mm}$

TH2 $20 \mu \mathrm{g}: 13 \mathrm{~mm}$

TH2 $10 \mu \mathrm{g}: 10 \mathrm{~mm}$

TH2 $5 \mu \mathrm{g}: 7 \mathrm{~mm}$

TH2 $2.5 \mu \mathrm{g}: 3 \mathrm{~mm}$
B

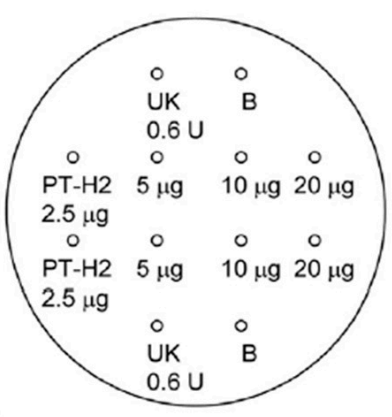

UK

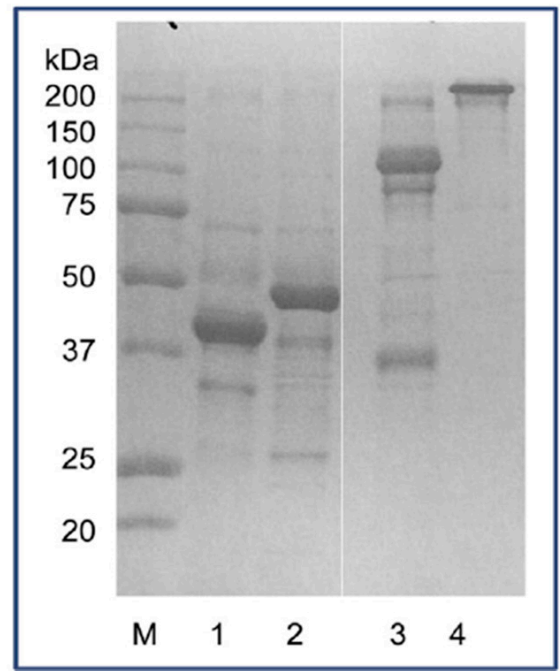

Figure 4. Effect of PT- $\mathrm{H}_{2}$ on bovine fibrin plates and SDS-PAGE of solutions that had been dissolved using $\mathrm{PT}-\mathrm{H}_{2}$ or urokinase. (A) Fibrinolytic activity of $\mathrm{PT}-\mathrm{H}_{2}$ and urokinase (as a positive control); (B) SDS-PAGE (Laemmli, 10\% gel, Coomassie Brilliant Blue staining) of solutions that had been dissolved using $\mathrm{PT}-\mathrm{H}_{2}$ (lane 2: reducing conditions, lane 4: non-reducing conditions) or urokinase (lane 1: reducing conditions, lane 3: non-reducing conditions). The assay of fibrinolytic activity was measured using the fibrin plate. A fibrin plate was prepared by the following methods. Bovine fibrinogen solution $(16 \mathrm{~mL}, 10 \mathrm{mg} / \mathrm{mL})$ in $0.02 \mathrm{M}$ Tris- $\mathrm{HCl}$ buffer $(\mathrm{pH} 7.5)$ containing $0.15 \mathrm{M} \mathrm{NaCl}$ and $5 \mathrm{mM} \mathrm{CaCl} 2$ was poured in a plate (internal diameter: $94 \mathrm{~mm}$ ). Then thrombin solution $(100 \mu \mathrm{L}$, 100 units $/ \mathrm{mL}$ ) was added to the plate, and clotted at $30^{\circ} \mathrm{C}$ for $2 \mathrm{~h}$. Sample solution containing the protein applied to the well, and incubated at $25^{\circ} \mathrm{C}$ overnight. After incubation, the fibrin plate was washed with saline three times, and then circle diameters dissolved by fibrinolytic enzyme and by urokinase as positive control were measured, respectively. Fluid from each circle dissolved by $\mathrm{PT}-\mathrm{H}_{2}$ protease or urokinase was sampled and then subjected to SDS-PAGE.

The fibrinolytic activation mechanisms of urokinase and $\mathrm{PT}-\mathrm{H}_{2}$ are obviously different. The results of sodium dodecyl sulfate polyacrylamide gel electrophoresis (SDS-PAGE) of fibrin that had been dissolved by $\mathrm{PT}-\mathrm{H}_{2}$ or urokinase are shown in Figure $4 \mathrm{~B}$. Urokinase completely digested the $\alpha, \beta$, and 
$\gamma$ chains of fibrin. In addition, the fibrin polymer was completely digested by urokinase, and fraction Y (molecular mass: $150 \mathrm{kDa}$ ), which is a fibrinogen/fibrin degradation product produced by plasmin, was released. On the other hand, PT- $\mathrm{H}_{2}$ completely digested the $\alpha$ and $\beta$ chains, but barely affected the $\gamma$ chain or the fibrin polymer [20].

\section{Hemorrhagic Activity}

Marked hemorrhaging, edema, necrosis, thrombogenesis, hypotension, and pain occur immediately after snakebites involving Viperidae and Crotalinae. Hemorrhagic SVMP have been isolated from many snake venoms and are considered to be one of the causes of the abovementioned symptoms. In vivo, hemorrhagic SVMP act on the peripheral vasculature, which causes red blood cells to leak from the affected blood vessels. Therefore, the hemorrhagic SVMP present in the snake venoms of Viperidae and Crotalinae are considered to be lethal factors. HR2a and HR2b (P-I SVMP), which have low molecular weights, and HR1A and HR1B (P-III SVMP), which have high molecular weights, were isolated from $P$. flavoviridis venom and characterized in a previous study [46]. The $\mathrm{H}_{2}$ proteinase (P-I SVMP) from the same snake venom $\left(\mathrm{PF}-\mathrm{H}_{2}\right)$, which has a low molecular weight, does not exhibit hemorrhagic activity [47]. The hemorrhagic activities of HR2a and HR2b (minimum hemorrhagic dose (MHD): $66 \mathrm{ng}$ in both cases) are about 6-10 times weaker than those of HR1A and HR1B (MHD: $11 \mathrm{ng}$ and $6.7 \mathrm{ng}$, respectively). Interestingly, the amino acid sequences of the $\mathrm{M}$ domains of four SVMP [18,22,23] isolated from P. flavoviridis venom displayed a high degree of homology compared with those of SVMP from other snake venoms (Figure 3). The differences in the hemorrhagic activity of these SVMP suggested that the DC domains of HR1A and HR1B influence their hemorrhagic activity. The hemorrhagic and proteolytic activities of P-I SVMP are generally weaker than those of P-III SVMP, whose C domains contain an HVR segment (positions 382-403 in Figure 3B). On the other hand, $\mathrm{PF}-\mathrm{H}_{2}$ and $\mathrm{PT}-\mathrm{H}_{2}$ do not exhibit hemorrhagic activity, although the amino acid sequences of these P-I SVMP demonstrate a high degree of homology, and they also share about 77\% homology with HR2a (Figure 3A). Furthermore, an array peculiar to amino acid sequences of non-hemorrhagic P-I SVMPs such as PF-H $\mathrm{H}_{2}$ proteinase and PT- $\mathrm{H}_{2}$ proteinase were admitted. On comparison between two non-hemorrhagic P-I SVMPs and M domains of hemorrhagic SVMPs such as HR1A and 1B, HR2a and $2 \mathrm{~b}, \mathrm{Lys}^{71}, \mathrm{Gln}^{93}$, Asn ${ }^{95}$, His ${ }^{99}$, Leu ${ }^{106}$, and Lys ${ }^{117}$ of two non-hemorrhagic P-I SVMPs are replaced by the amino acid residues of Glu (or Thr), Lys (or Arg), His, Gln, Phe, and Gly (or Ala), respectively. Most of the replaced amino acid residues are amino acids that influence protein-protein interactions between basic or hydrophobic amino acids. It is suggested that the hemorrhagic effects of P-I SVMP are controlled by theese amino acid residues. These amino acid residues are an important target for functional analyses of P-I SVMP.

\section{Inhibition of Platelet Aggregation}

Platelet aggregation is a key event in thrombus formation and is dependent on the binding of adhesive proteins to $\alpha \mathrm{IIb} \beta 3$ integrin molecules on the platelet surface. Platelet adhesion proteins, such as fibrinogen and von Willebrand factor, contain the tripeptide segment Arg-Gly-Asp (RGD) as a cell recognition site. Snake venom proteins, including disintegrins and SVMP, inhibit platelet aggregation $[48,49]$. Snake venom disintegrins are a family of non-enzymatic proteins from the snake venoms of Crotalinae and Viperidae. They were shown to contain the RGD or Lys-Gly-Asp (KGD) sequence in a homologous position and to inhibit the interaction between fibrinogen and $\alpha \mathrm{IIb} \beta 3$ integrin. Snake venom disintegrins bind to $\alpha \mathrm{Ilb} \beta 3$ integrin stronger than the RGD sequence of fibrinogen because the RGD sequences of these proteins are located on the top of the loop structure. Disintegrins were isolated from many snake venoms in the 1990s and have been actively researched [27]. In Japanese studies, four disintegrins, cytotoxic factor (CTF)-I, CTF-II [50], flavoridin [51], and triflavin [52], were detected in P. flavoviridis venom, and nine elegantin $[25,53]$ isoforms were isolated from P. elegans venom. 
On the other hand, P-I and P-III SVMP, which inhibit platelet aggregation, have been purified from the venoms of P. flavoviridis and P. elegans. In addition, HR1A, HR1B [22], and SV-PAD-2 [54], which are P-III SVMP, have been isolated from Protobothrops snake venom in Japan. HR1A and HR1B derived from $P$. flavoviridis venom undergo autoproteolysis and are released as single major fragments of 32 and $34 \mathrm{kDa}$, respectively, containing D and C domains. It is suggested that these fragments inhibit platelet aggregation [22]. The cDNA sequences of the D domain of flavoridin and the elegantin precursor [28,29] were classified as P-II SVMP [24] and exhibited a high degree of homology with the D domain of HR1A. Thus, it was suggested that snake venom disintegrins, such as flavoridin and elegantin, are generated from P-II or P-III SVMP after they have been cleaved autoproteolytically [24-26]. However, the RGD sequence of the disintegrin precursor is replaced with Arg-Ser-Glu, Glu-Ser-Glu, and Thr-Asp-Glu sequences in the D domains of HR1A, HR1B, and HV1, respectively (Figure 3B). Moreover, SV-PAD-2 from $P$. elegans venom had a marked effect on adenosine diphosphate (ADP)- and collagen-induced platelet aggregation (half maximal inhibitory concentrations [ $\mathrm{IC}_{50}$ ]: $240 \mathrm{nM}$ and $185 \mathrm{nM}$, respectively) and rapidly inhibited ADP-induced platelet aggregation. SV-PAD-2 can be subclassified as a P-IIIc SVMP based on the fact that it undergoes dimerization because its molecular mass according to SDS-PAGE was $110 \mathrm{kDa}$ under non-reducing conditions and $52 \mathrm{kDa}$ under reducing conditions [54].

Recently, it has been reported that P-I SVMP, such as barnettlysin-I (Bar-I) and Bothrops moojeni venom metalloproteinase (BmooMP) $\alpha$-II, inhibit ADP-, collagen- and ristocetin-induced platelet aggregation. BmooMP $\alpha$-II is a non-hemorrhagic P-I SVMP that inhibits platelet aggregation [55]. In addition, Bar-I is a 23,386 Da single-chain P-I SVMP that exhibits FL and hemorrhagic activity and inhibits platelet aggregation ( $\mathrm{IC}_{50}: 1.3 \mu \mathrm{M}$ for ristocetin-induced platelet aggregation; $3.2 \mu \mathrm{M}$ for collagen-induced platelet aggregation) [56]. Shanchez et al. suggested that Bar-I strongly inhibits platelet aggregation via the cleavage of $\alpha 2 \beta 1$ integrin, which is a selective collagen receptor [56]. Furthermore, we also recently found that PT- $\mathrm{H}_{2}$ inhibited ADP-induced platelet aggregation $\left(\mathrm{IC}_{50}: 8 \mu \mathrm{M}\right)$. As PT-H $\mathrm{H}_{2}$ inhibits platelet aggregation to a different extent to Bar-I, it is likely that PT- $\mathrm{H}_{2}$ inhibits platelet aggregation via a different mechanism from Bar-I. Many of the platelet aggregation inhibitors isolated from SVMP are disintegrin domain-containing P-II or P-III SVMP. In a recent investigation, I found that PT- $\mathrm{H}_{2}$ inhibited ADP-induced platelet aggregation. I suggest that PT- $\mathrm{H}_{2}$ also inhibits platelet aggregation via the cleavage of platelet integrins.

\section{Conclusions}

In this paper, we have described the structures and functions of SVMP derived from Protobothrops species ( $P$. flavoviridis (hon habu), P. elegans (sakishima habu), and P. tokarensis (tokara habu)) venom collected in Japan. The venoms of these snakes contain many SVMPs that exhibit a variety of physiological and biological functions. SVMPs range in size from 20 to $100 \mathrm{kDa}$ and have been classified into three groups, P-I to P-III, according to their M, D, and C domain characteristics. P-III SVMP display various physiological functions associated with the DC domain. In the current study, it was suggested that the DC domain (especially the HVR segment in the C domain) influences the substrate specificity of SVMP, and the M domain is thought to function like a pair of scissors during substrate cleavage. However, P-I SVMP that displayed various substrate specificities were recently purified from several snake venoms.

As for the amino acid sequences of the SVMP found in Protobothrops venom, most differences were detected in the M domain, so it may be considered that the functions of SVMP are influenced by these particular amino acid residues in the M domain. The SVMPs isolated from all Protobothrops venoms collected in Japan exhibited similar structures. The SVMPs examined in the present study might be useful for clarifying the relationship between the $\mathrm{M}$ domain architecture and function.

Acknowledgments: We are grateful to Satohiko Araki and Naoko Ueda for their excellent technical assistance.

Conflicts of Interest: The authors declare no conflict of interest. 


\section{References}

1. Kini, R.M. Anticoagulant proteins from snake venoms: Structure, function, and mechanism. Biochem. J. 2006, 397, 377-387. [CrossRef] [PubMed]

2. Jia, L.G.; Wang, X.M.; Shannon, J.D.; Biarnason, J.D.; Fox, J.W. Inhibition of platelet aggregation by the recombinant cysteine-rich domain of the hemorrhagic snake venom metalloproteinase, atrolysin A. Arch. Biochem. Biophys. 2000, 373, 281-286. [CrossRef] [PubMed]

3. Takeda, S.; Takeya, H.; Iwanaga, S. Snake venom metalloproteinases: Structure, function and relevance to the mammalian ADAM/ADAMTS family proteins. Biochim. Biophys. Acta 2012, 1824, 164-176. [CrossRef] [PubMed]

4. Hite, L.A.; Jia, L.-G.; Bjarnason, J.B.; Fox, J.W. cDNA sequences for four snake venom metalloproteinases: Structure, classification, and their relationship to mammalian reproductive proteins. Arch. Biochem. Biophys. 1994, 308, 6203-6211. [CrossRef] [PubMed]

5. Iwanaga, S.; Suzuki, T. Enzymes in snake venom. In Handbook of Experimental Pharmacology; Born, G.V.R., Farah, A., Herken, H., Welch, A.D., Eds.; Springer: New York, NY, USA, 1979; Volume 52, pp. 61-158.

6. Bjarnason, J.B.; Fox, J.W. Hemorrhagic metalloproteinases from snake venoms. Pharmacol. Ther. 1994, 62, 325-372. [CrossRef]

7. Fox, J.W.; Serrano, S.M. Structural considerations of the snake venom metalloproteinases, key members of the M12 reprolysin family of metalloproteinases. Toxicon 2005, 45, 969-985. [CrossRef] [PubMed]

8. Fox, J.W.; Serrano, S.M. Timeline of key events in snake venom metalloproteinase research. J. Proteom. 2009, 72, 200-209. [CrossRef] [PubMed]

9. Takeya, H.; Iwanaga, S. Proteases that induce hemorrhagic. In Enzymes from Snake Venom; Bailey, G.S., Ed.; Alaken: Fort Collins, CO, USA, 1998; pp. 11-38.

10. Araki, S.; Masuda, S.; Maeda, H.; Ying, M.J.; Hayashi, H. Involvement of specific integrins in apoptosis induced by vascular apoptosis-inducing protein 1 . Toxicon 2002, 40, 535-542. [CrossRef]

11. Fox, J.W.; Serrano, S.M. Snake venom metalloproteinase. In Handbook of Venoms and Toxins of Reptiles; Mackessy, S.P., Ed.; CRC Press: Boca Raton, FL, USA, 2010; pp. 95-113.

12. Kang, T.S.; Georgieva, D.; Genov, N.; Murakami, M.T.; Sinha, M.; Kumar, R.P.; Kaur, P.; Kumar, S.; Dey, S.; Sharma, S.; et al. Enzymatic toxins from snake venom: Structural characterization and mechanism of catalysis. FEBS 2011, 278, 4544-4576. [CrossRef] [PubMed]

13. Bjarnason, J.B.; Fox, J.W. Snake venom metalloproteinases: Reprolysins. Methods Enzymol. 1995, 248, $345-368$. [PubMed]

14. Kishimoto, M.; Takahashi, T. Molecular cloning of HR1a and HR1b, high molecular hemorrhagic factors, from Trimeresurus flavoviridis venom. Toxicon 2002, 40, 1369-1375. [CrossRef]

15. Takeya, H.; Oda, K.; Miyata, T.; Omori-Satoh, T.; Iwanaga, S. The complete amino acid sequence of the high molecular mass hemorrhagic protein HR1B isolated from the venom of Trimeresurus flavoviridis. J. Biol. Chem. 1990, 265, 16068-16073. [PubMed]

16. Takeya, H.; Nishida, S.; Miyata, T.; Kawada, S.; Saisaka, Y.; Morita, T.; Iwanaga, S. A novel metalloproteinase with disintegrin (platelet aggregation inhibitor)-like and C-type lectin-like domains. J. Biol. Chem. 1992, 267, 14109-14117. [PubMed]

17. Gowda, D.C.; Jackson, C.M.; Hensley, P.; Davidson, E.A. Factor X-activating glycoprotein of Russell's viper venom. Polypeptide composition and characterization of the carbohydrate moieties. J. Biol. Chem. 1994, 269, 10644-10650. [PubMed]

18. Gomis-Ruth, F.X. Structural aspects of the metzincin clan of metalloendopeptidases. J. Mol. Biotechnol. 2003, 24, 157-202. [CrossRef]

19. Kumasaka, T.; Yamamoto, M.; Moriyama, H.; Tanaka, N.; Sato, M.; Katsube, Y.; Yamakawa, Y.; Omori-Satoh, T.; Iwanaga, $\mathrm{S}$.; Ueki, T. Crystal structure of $\mathrm{H}_{2}$-proteinase from the venom of Trimeresurus flavoviridis. J. Biochem. 1996, 119, 49-57. [CrossRef] [PubMed]

20. Oyama, E.; Kitagawa, Y.; Takahashi, H. Primary structure and characterization of a non hemorrhagic metalloproteinase with fibrinolytic activity, from the snake venom of Protobothrops tokarensis (Tokara-habu). Toxicon 2013, 70, 153-161. [CrossRef] [PubMed] 
21. Takeya, H.; Arakawa, H.; Miyata, T.; Iwanaga, S.; Omori-Satoh, T. Primary structure of $\mathrm{H}_{2}$-proteinase, a non-hemorrhagic proteinase, isolated from the venom of the habu snake, Trimeresurus flavoviridis. J. Biochem. 1989, 106, 843-853. [CrossRef]

22. Miyata, T.; Takeya, H.; Ozeki, Y.; Arakawa, M.; Tokunaga, F.; Iwanaga, S.; Omori-Satoh, T. Primary structure of hemorrhagic protein, HR2a, isolated from the venom of Trimeresurus flavoviridis. J. Biochem. 1989, 105, 847-853. [CrossRef] [PubMed]

23. Iha, M.; Qi, Z.Q.; Kannki, T.; Tomihara, Y.; Yonaha, K. The primary structure of a hemorrhagic factor, HR2b, from the venom of Okinawa habu (Trimeresurus flavoviridis). Toxicon 1995, 33, 229-239. [CrossRef]

24. Kishimoto, M.; Takahashi, T. Molecular cloning and sequence analysis of cDNA encoding flavoviridin, a disintegrin from the venom of Trimeresurus flavoviridis. Toxicon 2002, 40, 1033-1040. [CrossRef]

25. Scaloni, A.; Di Martino, E.; Miraglia, N.; Pelagalli, A.; Della Marte, R.; Staiano, N.; Pucci, P. Amino acid sequence and molecular modelling of glycoprotein IIb-IIIa and fibronectin receptor iso-antagonists from Trimeresurus elegans venom. Biochem. J. 1996, 313, 775-782. [CrossRef]

26. Masuda, S.; Hayashi, H.; Atoda, H.; Morita, T.; Araki, S. Purification, cDNA cloning and characterization of the vascular apoptosis-inducing protein, HV1, from Trimeresurus flavoviridis. Eur. J. Biochem. 2001, 268, 3339-3345. [CrossRef] [PubMed]

27. Takeda, S.; Igarashi, T.; Mori, H.; Araki, S. Crystal structure of VAP1 reveal ADAMs MDC domain architecture and its unique C-shaped scaffold. EMBO J. 2006, 25, 2388-2396. [CrossRef] [PubMed]

28. Takeda, S. Three-dimensional domain architecture of the ADAM family proteinases. Semin. Cell Dev. Biol. 2009, 20, 146-152. [CrossRef] [PubMed]

29. Takeya, H.; Nishida, S.; Nishino, S.; Makinose, Y.; Omori-Satoh, T.; Nikai, T.; Sugihara, H.; Iwanaga, S. Primary structures of platelet aggregation inhibitors (disintegrin) autoproteolytically released from snake venom hemorrhagic metalloproteinases and new fluorogenic peptide substrates for these enzyme. J. Biochem. 1993, 113, 473-483. [CrossRef] [PubMed]

30. Hite, L.A.; Shannon, J.D.; Biarnason, J.B.; Fox, J.W. Sequence of a cDNA clone encoding the zinc metalloproteinase hemorrhagic toxin e from Crotalus atrox: Evidence for signal, zymogen, and disintegrin-like structures. Biochemistry 1992, 31, 6203-6211. [CrossRef] [PubMed]

31. Kini, R.M.; Evans, H.J. Structural domains in venom proteins: Evidence that metalloproteinases and nonenzymatic platelet aggregation inhibitors (disintegrins) from snake venom are derived by proteolysis from a common precursor. Toxicon 1992, 30, 265-293. [CrossRef]

32. Okuda, D.; Koike, H.; Morita, T. A new gene structure of the disintegrin family: A subunit of dimeric disintegrin has a short coding region. Biochemistry 2002, 41, 14248-14254. [CrossRef] [PubMed]

33. Huang, T.F.; Holt, J.C.; Lukasiewicz, H.; Niewiarowski, S. Trigramin. A low molecular weight peptide inhibiting fibrinogen interaction with platelet receptors expressed on glycoprotein Ilb-IIIa complex. J. Biol. Chem. 1987, 262, 16157-16163. [PubMed]

34. Calvete, J.J.; Marcinkiewicz, C.; Monleon, D.; Esteve, V.; Celba, B.; Juarez, P.; Sanz, L. Snake venom disintegrins: Evolution of structure and function. Toxicon 2005, 45, 1063-1074. [CrossRef] [PubMed]

35. Siigur, E.; Siigur, J. Purification and characterization of lebetase, a fibrinolytic enzyme from Vipera lebetina (snake) venom. Biochim. Biophys. Acta 1991, 1074, 223-229. [CrossRef]

36. Esnouf, M.P.; Tunnah, G.W. The isolation and properties of the thrombin-like activity from Angistrodon rhodostoma venom. Br. J. Haematol. 1967, 13, 582-590. [CrossRef]

37. Markland, F.S.; Damus, P.S. Purification and properties of a thrombin-like enzyme from the venom of Crotalus adamanteus (Eastern diamondback rattlesnake). J. Biol. Chem. 1971, 246, 6460-6473. [PubMed]

38. Oyama, E.; Takahashi, H. Substrate specificity of two thrombin like enzymes (elegaxobin, elegaxobinII) from the venom of Trimeresurus elegans (Sakishima-habu), using neutralizing antibody. Toxicon 2006, 48, 601-610. [CrossRef] [PubMed]

39. Zhang, Y.; Wisner, A.; Maroun, R.C.; Choumet, V.; Xiong, Y.; Bon, C. Trimeresurus stejnegeri snake venom plasminogen activator. J. Biol. Chem. 1997, 272, 20531-20537. [CrossRef] [PubMed]

40. Sanchez, F.F.; Santos, C.I.; Magalhaes, A.; Diniz, C.R.; Figueiredo, S.; Gilroy, J.; Richardson, M. Isolation of a proteinase with plasminogen-activating activity from Lachesis muta muta (Bushmaster) snake venom. Arch. Biochem. Biophys. 2000, 378, 131-141. [CrossRef] [PubMed]

41. Robbins, K.C.; Summaria, L.; Hsieh, B.; Shah, R.J. The peptide chains of human plasmin. Mechanism of activation of human plasminogen to plasmin. J. Biol. Chem. 1967, 242, 2333-2342. [PubMed] 
42. Forsgren, M.; Raden, B.; Israelsson, M.; Larsson, K.; Heden, L.O. Molecular cloning and characterization of a full-lengh cDNA clone for human plasminogen. FEBS Lett. 1987, 213, 254-260. [CrossRef]

43. Nikai, T.; Mori, N.; Kishida, M.; Yuko, K.; Takenaka, C.; Murakami, T.; Shigezane, S.; Sugihara, H. Isolation and characterization of hemorrhagic factors and $\mathrm{b}$ from the venom of the Chinese habu snake (Trimeresurus mucrosquamatus). Biochim. Biophys. Acta 1985, 838, 122-131. [CrossRef]

44. Nikai, T.; Mori, N.; Kishida, M.; Sugihara, H.; Tu, A.T. Isolation and biochemical characterization of hemorrhagic toxin $\mathrm{f}$ from the venom of Crotalus atrox (western diamondback rattlesnake). Arch. Biochem. Biophys. 1984, 231, 309-319. [CrossRef]

45. Kim, J.-Y.; Lee, S.-B.; Kwon, K.R.; Choi, S.-H. Isolation and Characterization of a 32-kDa fibrinolytic enzyme (FE-32 kDa) from Gloydius blomhoffii siniticus venom. Pharmacopuncture 2014, 17, 44-50. [CrossRef] [PubMed]

46. Ohsaka, A. Handbook of Experimental Pharmacology, Snake Venoms; Lee, C.-Y., Ed.; Springer-Verlag: New York, NY, USA, 1979; Volume 52, pp. 480-546.

47. Takahashi, T.; Ohsaka, A. Purification and characterization of a proteinase in the venom of Trimeresurus flavoviridis. Complete separation of the enzyme from hemorrhagic activity. Biochim. Biophys. Acts 1970, 198, 293-307. [CrossRef]

48. Kini, R.M.; Evans, H.J. Effects of snake venom proteins on blood platelets. Toxicon 1990, 28, 1387-1422. [CrossRef]

49. Teng, C.M.; Huang, T.F. Snake venom constituents that affect platelet function. Platelets 1991, 2, 77-87. [CrossRef] [PubMed]

50. Yamakawa, Y.; Omori-Satoh, T.; Maeyama, J. Primary structures of cytotoxic factors isolated from Habu (Trimeresurus flavoviridis) venom. J. Biochem. 1991, 109, 667-669. [CrossRef] [PubMed]

51. Musial, J.; Niewiarowski, S.; Rucinski, B.; Stewart, G.J.; Cook, J.J.; Williams, J.A.; Edmunds, L.H., Jr. Inhibition of platelet adhesion to surfaces of extracorporeal circuits by disintegrins. RGD-containing peptides from viper venoms. Circulation 1990, 82, 261-273. [CrossRef] [PubMed]

52. Huang, T.F.; Sheu, J.R.; Teng, C.M.; Chen, S.W.; Liu, C.S. Triflavin, an antiplatelet Arg-Gly-Asp-containing peptide, is a specific antagonist of platelet membrane glycoprotein IIb-IIIa complex. J. Biochem. 1991, 109, 328-334. [PubMed]

53. Williams, J.; Rucinski, B.; Holt, J.; Niewiarow, S. Elegantin and albolabrin purified peptides from viper venoms: Homologies with the RGDS domain of fibrinogen and von Willebrand factor. Biochim. Biophys. Acta 1990, 31, 81-89. [CrossRef]

54. Oyama, E.; Takahashi, H. Purification and characterization of two high molecular mass snake venom metalloproteinase (P-III SVMPs), named SV-PAD-2 and HR-Ele-1, from the venom of Protobothrops elegans (Sakishima-habu). Toxicon 2015, 103, 30-38. [CrossRef] [PubMed]

55. Queiroz, M.R.; Mamede, C.C.; Fonseca, K.C.; De Morais, N.C.G.; De Sousa, B.B.; Santos-Filbo, N.A.; Beletti, M.E.; Arantes, E.C.; Stanziola, L.; De Oliveira, F. Rapid purification of a new P-I Crass metalloproteinase from Bothrops moojeni venom with antiplatelet activity. BioMed Res. Int. 2014, 2014, 352420. [CrossRef] [PubMed]

56. Sanchez, E.F.; Richardson, M.; Gremski, L.H.; Veiga, S.S.; Yarleque, A.; Niland, E.S.; Lima, A.M.; Estevao-Costa, M.I.; Eble, J.A. A novel fibrinolytic metalloproteinase, barnettlysin-1 from Bothrops barnetti (barnett's pitviper) snake venom with anti-platelet properties. Biochim. Biophys. Acta 2016, 1860, 542-556. [CrossRef] [PubMed]

(C) 2017 by the authors. Licensee MDPI, Basel, Switzerland. This article is an open access article distributed under the terms and conditions of the Creative Commons Attribution (CC BY) license (http:/ / creativecommons.org/licenses/by/4.0/). 